\title{
IBN HִAZM EN CÓRDOBA Y LOS RASGOS TÍPICOS DEL TOPOS DEL AMOR
}

\section{IBN HִAZM IN CORDOBA AND THE TYPICAL FEATURES OF THE TOPOS OF LOVE}

\author{
ابن حزم بقرطبة وسمات نموذجية لمواضيع الحب \\ Letizia LOMBEZZI* \\ Libera Università di Bolzano-Italia
}

BIBLID [1133-8571] 27 (2020) 104.1-13

Resumen: Se propone una relectura de la obra de Ibn Hazm y de las contaminaciones literarias relacionadas con el tópico del amor, guiada por factores históricos más que artísticos. De hecho, el autor vivió el periodo más tormentoso de la historia de al-Andalus, conocido como la era de los mulūk al-țawāiff, la cual se caracteriza por las luchas y rivalidades para conquistar el poder en la Península Ibérica. La ciudad de Córdoba toma un papel central, tanto de eje político principal como de centro cultural, donde Ibn Hazm recibió el legado de la cultura y literatura árabo-islámica que luego le fue transmitido a la literatura europea. Un antecedente histórico importante, que seguramente favoreció las contaminaciones entre los dos repertorios literarios, árabe y europeo, se reconoce en la batalla de Barbastro. Después de tal evento, numerosas cantantes, qiyān, fueron deportadas como botín de guerra a las cortes de la Francia meridional, llevándose consigo el conocimiento artístico y literario y favoreciendo el desarrollo de la poesía trovadoresca. La comparación entre versos de las líricas de trovadores y del Collar de Ibn Hazm sugiere, por lo menos, la hipótesis de una contaminación debida a procesos de intertextualidad e interdiscursividad, si no de contacto directo.

Palabras clave: Poesía árabe. Amor cortés. Ibn Ḥazm. Trovadores. Reinos de Taifas.

Abstract: Ibn Hazm in Cordoba and the typical features of the love topic. Ibn Hazm in Cordoba and the typical features of the topic of love. This article offers a rereading of the work by Ibn Hazm, and the literary contaminations related to the topic of love, guided by historical factors rather than artistic ones. In fact, the author lived during the stormiest period in the history of al-Andalus, known as the mulük al-tawāi if era, characterized by struggles and rivalries for power in the Iberian Peninsula. The city of Cordoba played the role of the main political axis and the cultural center, where the legacy of the Arab-Islamic culture and literature was received by Ibn Hazm, and then transmitted to European literature. In this regard, the Battle of Barbastro should be considered an important historical antecedent that surely favored contaminations between the two literary repertoires. After such an event, many singers (qiȳan), were deported to the courts of Southern France, taking with them their artistic and literary background, and favoring the emergence and development of troubadour poetry. The comparison between the lyrics of troubadours and the texts of the Collar by Ibn Hazm suggests, at least, the hypothesis of a contamination due to intertextuality and interdiscursiveness, if not direct contact..

Key words: Arabic poetry. Courtly love. Ibn Hazm. Troubadours. Taifa kingdoms.

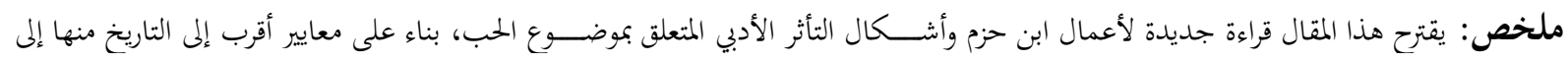

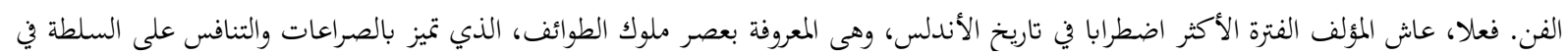

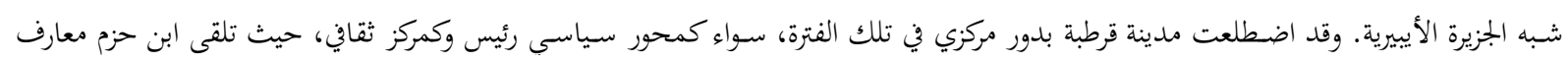

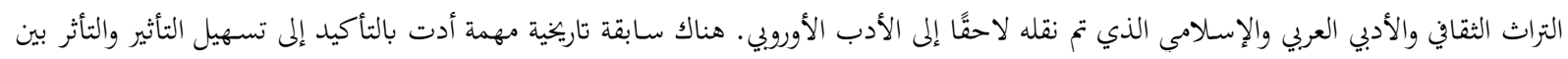

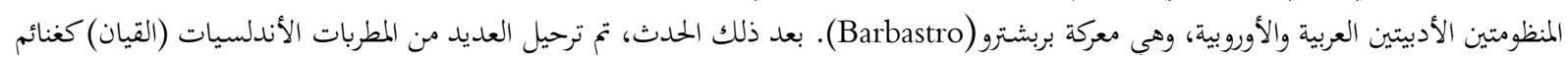

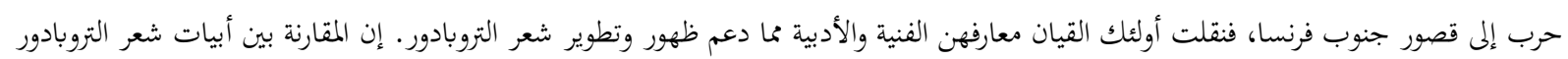

* $\quad$ E-mail: letizia.lombezzi@unibz.it. 


$$
\begin{aligned}
& \text { ونصوص طوق الحمامة لابن حزم تفتح المجال لفرضية وجود شيء من التأثير والتأثر العائد إلى عمليات التناص وتداخل الخطاب الأدبي، إن لم يعد ذلك } \\
& \text { إلى الاتصال المباشر بين الجنسين الأدبيين. } \\
& \text { كلمات مفاتيح: الشعر العربي. الحب النبيل. ابن حزم. التروبادور. ملوك الطوائف. }
\end{aligned}
$$

\section{Introducción}

Ibn Hazm vivió el periodo más tormentoso de la historia de al-Andalus, conocido como la era de los mulūk al-tawāîf, los Reinos de Taifas, la cual se caracteriza por las luchas y rivalidades para conquistar el poder en la parte andalusí de la Península Ibérica. La ciudad de Córdoba fue al mismo tiempo un eje político y un centro cultural, donde el legado de la cultura y literatura árabo-islámica fue recibido y luego transmitido hacía la literatura europea. Al respecto, algunos eruditos reconocen en la batalla de Barbastro (taifa de Lérida, 1064) un evento facilitador de contaminación literaria. Uno de los líderes de los cristianos fue el duque de Aquitania, Guillermo VIII, predecesor de Guillermo IX el trovador. Los "cruzados" conquistaron Barbastro y capturaron mucho botín y mujeres, incluidas las cantantes de corte (qiyān). Ellas continuaron sus trabajos en las cortes del sur de Francia, y exportaron así sus repertorios artísticos compuestos por temas y formas poéticas árabes.

Generalmente, el nivel de contaminación entre obras ha sido alto en la historia de la literatura, donde la intertextualidad se destaca como un procedimiento adoptado frecuentemente y con lo cual se construye una trama narrativa compleja. ${ }^{(1)}$ El estudio de la intertextualidad se basa en el deconstruccionismo elaborado por el filósofo Derrida: la observación de que significante y significado ya no representan una pareja fija con correspondencia única, por el contrario están bien separados y difícilmente pueden reunirse. En la práctica, existe una différance entre la obra, material muerto y el texto, que se puede interpretar con una referencia continua de significados, su superposición, su juego de referencias y variaciones.

Este mismo razonamiento fue aplicado a la crítica literaria árabe por el marroquí Kilito en su El autor y sus dobles. Kilito afirmó que el autor (el poeta) "se basa en un dibujo". ${ }^{(2)}$ Las huellas de los que nos precedieron, incluso en el sentido literario, no desaparecen, sino que se absorben temporalmente y siempre están listas para manifestarse nuevamente. El papel del arte y de la literatura, dice Kilito, es simplemente poner en orden estos elementos, antiguos y nuevos.

Teniendo en cuenta estos supuestos teóricos y mediante unos paralelismos temáticos que emergen de pasajes específicos tomados de varias obras, se puede comprobar la transmisión cultural y las interferencias entre el amor cortés árabe y europeo del siglo XII, ya que, de hecho, huellas árabes se encuentran en la literatura francesa y trovadoresca.

\section{El califato de Córdoba, desde los Omeyas hasta los reyes de taifas}

En Córdoba se han dado cita turbulentas vicisitudes, a lo largo de las cuales la ciudad ha ido confirmando su papel como bastión omeya. El período aquí examinado (929-1031) resume los principales eventos con el objetivo de subrayar los antecedentes y las rivalidades en la sucesión del poder.

El primer personaje importante es el califa ${ }^{\complement} \mathrm{Abd}$ al-Raḥmān al-Nāsir li-dīn Allāh, que fue capaz de mantener su hegemonía en la Península y también ocupó Ceuta en 931. Extendió el número de palacios califales en Córdoba y engrandeció la Gran Mezquita. A su muerte en 961, lo sucedió su hijo al-Mustanșir bi-l-Lāh, quien tuvo que enfrentar las revueltas de los cristianos de Navarra, León y el condado de Barcelona. al-Mustanșir los derrotó y Córdoba mantuvo su

(1) Brugnolo et alii (2016): La scrittura e il mondo, pp. 284-291.

(2) Kilito (1988): L'autore e i suoi doppi, p.19. 
papel como líder de la Península Ibérica. Hubo, sin embargo, un precio de coste, que luego se reveló un error político: al-Mustanșir contrató numerosos mercenarios bereberes y, al mismo tiempo, a su muerte, dejó el califato en herencia a su hijo Hišām, un niño. Se abrió una lucha dinástica entre Hišām y su tío, en la que el primer ministro de Hišām, Ğa ${ }^{\varsigma} f a r$ b. ${ }^{\varsigma} U t \underline{t} a ̄ n$ alMuṣhafî, consiguió maniobrar en el poder para nombrar un administrador factótum de confianza y muy fiel, exjefe de la policía, Muhammad Ibn Abī ${ }^{\complement} \bar{A} m i r$. Este último se libró de Ğa`far en poco tiempo, cuando lo hizo arrestar y mantuvo formalmente a Hišām, con apariciones públicas como califa, para el sermón del viernes, e imprimiendo dinero a su nombre. Muhammad Ibn $A b \overline{1}{ }^{\complement} \bar{A}$ mir asumió el título de al-Manșūr y el gobierno desde 977 hasta 1002, inaugurando la dinastía amirí. Como esta dinastía había arrebatado el poder a los Omeyas, no podía seguir utilizando a los antiguos sirvientes militares, que reemplazó rápidamente con bereberes. También aplastó a la oposición cristiana atacando Navarra, León y Castilla y, como estrategia diplomática, los soberanos de los dos primeros ofrecieron sus hijas como esposas al visir. al-Manșūr continuó la política de los visires anteriores en el Norte de África, particularmente en Ceuta, donde el gobernador designado por los Fatimíes se vio obligado a retirarse. También se ocupó de los asuntos culturales, construyendo un asiento adicional para las artes en al-Zāhira, no lejos de Madīna al-Zahrāè, y amplió la Gran Mezquita de Córdoba. Los Omeyas y sus fieles, expertos en la gestión del estado, fueron eliminados por completo y se perdió su habilidad y experiencia. A la muerte de al-Manșūr, su hijo, al-Mud̦affar (10021008) heredó el poder y continuó con éxito la lucha contra los reinos cristianos. También inauguró una política de colonización, que prometía ayuda estatal para aquellos que se habían trasladado a las tierras conquistadas para desarrollarlas o cultivarlas. Cuando murió alMudaffar, estalló el levantamiento bereber, facilitado por el gran número de estos que a la sazón ingresaron con un papel decisivo en el ejército mercenario. El poder estaba formalmente en manos del hermano de al-Mudaffar, ' $A$ Abd al-Raḥmān. Además, el califa niño mencionado anteriormente, Hišām, ya había crecido.

'Abd al-Raḥmān, hermano de al-Mudaffar, obligó a Hišām a nombrarlo por decreto su heredero, lo que desencadenó la reacción de los partidarios de la facción omeya, liderada por un marwaní al-Mahdī bi-l-Lāh, que atacó el palacio de Córdoba y después al-Zāhira. En 1009 terminó la dinastía amirí, en la cual también había servido el padre de Ibn Hazm. Al-Mahdī cometió el error de maltratar a los bereberes, rivales por haber apoyado a los amiríes, pero peligrosos porque eran numéricamente preponderantes. No obstante, los bereberes apoyaron a Sulaymān al-Musta`īn, un omeya rival, que a su vez dividió las tierras entre las tribus bereberes. Este evento inauguró el nacimiento embrionario de los Reinos de Taifas, que luego se reafirmó después de la caída de Córdoba, en 1031, y hasta 1091. El período entre el declive de los amiríes y el auge de las facciones fue vivido por Ibn Hazm, ya ocupado componiendo El Collar. Las facciones y los territorios pueden distribuirse de la siguiente manera: la aristocracia árabe, en Sevilla, Zaragoza, Almería, Murcia; los clientes omeyas de Córdoba; la facción amirí de Valencia y Baleares; la facción bereber establecida en el oeste, en Toledo, Santaver, Huete, Cuenca, Uclés; los mercenarios bereberes soldados de profesión, cerca de Granada, Zanata, Carmona, Ronda, La Frontera de Arcos; los “bereberes árabes”, en Marruecos, en Málaga, en Algeciras.

El sitio de Barbastro (Huesca), que formaba parte de la taifa de Lérida y fue atacado por una coalición de franceses, borgoñones e italo-normandos en 1064. El año anterior el papa Alejandro II había sancionado la 'emergencia cristiana' de la reconquista prometiendo indulgencias a los soldados que participaran en la expedición de reconquista. Entonces, Barbastro representa una proto-cruzada, en comparación a la declarada más tarde por Urbano II, y seguramente la primera cruzada de España. Uno de los líderes de los cristianos fue el duque de Aquitania, Guillermo VIII, predecesor de Guillermo IX, llamado el trovador. Los cruzados 
conquistaron el sitio y capturaron mucho botín y mujeres, incluidas las cantantes de la corte (qiyān) ya mencionadas. Ellas continuaron sus trabajos en las cortes del sur de Francia, y exportaron así sus repertorios artísticos compuestos de temas y formas poéticas árabes. En 1065 los musulmanes contratacaron y recuperaron la ciudad.

\section{Vida y obra de Ibn Ḥazm}

Ibn Hazm era hijo de un visir que había servido en el estado amirí con al-Manșūr y alMud̦affar. Hijo de noble familia, como él mismo escribió al cadí Abū l-Qāsim Sa`īd b. Aḥmad:

"nací en Cordoba, en la parte oriental, en el arrabal de Munyat al-Mugīira, antes de la salida del sol y después de la salutación del imán en la oración del amanecer (al-ṣubh), al final de la noche del miércoles, último día de la luna del espléndido mes de ramadán que corresponde al 7 de noviembre [sic] del año 384 (=7 de noviembre 994) con Escorpión de ascendente".

Su primera entrada en la escena literaria se remonta al día en el que Ibn Hazm en persona se encontró en la corte de al-Mudaffar, donde pudo escuchar el poema de alabanza que Șa $a^{\Upsilon} \overline{1} d$ de Bagdad compuso para el gobernador de Córdoba. Al respecto, García Gómez nos proporciona una referencia tomada de la $\breve{G} a \underline{d} w a t$ al-muqtabis de Humaydī. Efectivamente, leemos en el pasaje relativo a la biografía de $\mathrm{Sa}^{\Upsilon}{ }^{\complement} \mathrm{i}$ :

Abū Muhammad ${ }^{\complement} A l \overline{1}$, hijo del visir Abū ${ }^{\complement} U m a r$ Aḥmad ibn Sa`̄̄e ibn Hazm, me contó haber oído a Abū 1${ }^{\complement} A \bar{a}^{2}$ Ṣa ${ }^{\complement} \overline{1} d$ ibn al-Hasan recitar esta qașīda delante de al-Mud̦affar el día de la fiesta de la ruptura del ayuno del año 396. Ese día -me dijo Abū Muḥammad- fue el primero en que llegué a presencia de al-Mud̦affar, y cuando Abū $l^{\complement}{ }^{\complement} A \bar{a}^{?}$ vió que me gustaba la qașīda y que la escuchaba con atención, me la escribió de su puño y letra y me la hizo llegar.

Deducimos, de la mención explícita de la fecha, que el evento tuvo lugar el $1^{\circ}$ de julio de 1006; Ibn Hazm tenía doce años y ya participaba en las fiestas de la corte.

Un poco más tarde su familia cayó en desgracia, con el destronamiento del califa Hišām II y la subida de al-Mahdī, en 1009. Posteriormente, los bienes de la familia fueron incautados. Desde este momento la familia de Ibn Hazm se dedicó a luchar contra los eslavos, sin éxito. Después de las muertes de su padre y su hermano se mudó a Almería en 1013 y asistió a compañeros e intelectuales en Málaga.

Ibn Ḥazm, del partido omeya, apoyó el regreso de ${ }^{\varsigma} A b d$ al-Raḥmān IV al-Murtaḍà. En la batalla, fue tomado prisionero en Granada y cuando lo liberaron se retiró a Játiva, donde probablemente compuso su obra. Por dos veces más fue nombrado visir, pero su vida política y la de sus protectores estuvieron marcadas por continuas pérdidas de poder. Después del califato de al-Mustazhir, fue encarcelado de nuevo en 1024. Recobrada la libertad decidió dedicarse a la escritura y el estudio, y a partir de este período tenemos más noticias de sus libros que de su vida. El período entre 1041-1054 lo pasó como ‘intelectual vagabundo' según García Gómez, entre Córdoba, Almería, Talavera y Mallorca, aquí participando en controversias religiosas hasta 1049. Después se trasladó a Denia y Sevilla. De hecho, tras el final del califato de Córdoba, comenzó la era de las taifas, los mulūk al-țawā’if, durante la cual Ibn Hazm se retiró a Munt Lišām, identificada por Asín con Casa Montija ( Huelva).

En el Tawq al-hamāma («El collar de la paloma») se encuentran los temas literarios de la superioridad de la amada y el tema de un amante sumiso a la voluntad de la amada misma. Se trata del tópico del amor sin recompensa y entendido como sufrimiento. Aunque la pasión amorosa aparezca también en la lírica griega (Safo) y latina (Catulo, Horacio, Ovidio), en Ibn Hazm y luego en la lírica del amor cortés, tal pasión se caracteriza más como sufrimiento y 
enfermedad. Se trata de una concepción idealizada del amor, ya parcialmente aparecida en la época preislámica, así como en la poesía ' $u \underline{d} r \bar{i}$.

En su obra, Ibn Hazm (994-1063) habla de su vida y de los efectos del amor en su alma. Empieza por la definición de la naturaleza del amor, y luego describe sus síntomas y causas (māhiyyat al- $\imath_{i \check{s} q}$ ). Describe el enamoramiento, que tiene lugar a través de etapas concretas ( $a h w \bar{a} l)$, que el autor acompaña con anécdotas (habar) de alto valor literario.

El amor se caracteriza como enfermedad, la actitud del enfermo es la humildad, sus virtudes el perdón, fidelidad y paciencia, y su requisito fundamental es la capacidad de guardar el secreto de tal pasión. Los corazones de los amantes representan dos mitades de una esfera, según la antigua concepción platónica, y la belleza del amor se guarda evitando el pecado. El sentimiento se transmite a través de los ojos que envían señales a la amada, y también las reciben. Estas cuestiones preliminares se encuentran en los primeros dos libros, siendo los siguientes dedicados a temas más específicos. Efectivamente, la obra aborda los temas de:

-el enamoramiento (libros 3-7), donde la visión de la amada se aparece o bien consiste en un sueño;

-la comunicación del sentimiento (libros 8-12), a través de alusiones, señales con los ojos, correspondencia entre los amantes, o gracias al papel de un mensajero;

-la reflexión de si será mejor guardar el secreto o revelar el amor (libro 13);

-la reacción de la amada como complicidad (14) o rechazo (15);

-el debate sobre cuál ha de ser la actitud que alimente mejor el amor (15);

-el papel de quien rechaza el sentimiento y el efecto surtido por tal rechazo (16);

-los personajes del ayudante (17), el espía (18), el difamado o el comprometido (19);

-el tema de la unión (20) entendida como la superación de obstáculos y la discusión sobre la legitimidad de las uniones sexuales;

-el "tiempo de ruptura" (21) pero con alusiones para comprobar la paciencia y la fidelidad, por ejemplo, a través de acusaciones falsas, que comprueben la humildad del amante;

-el tema de la fidelidad (22);

-la traición (23);

-la separación (24);

-la satisfacción (25);

-la melancolía motivada por el desgaste y el sufrimiento (26);

-el olvido (27);

-la muerte por el sufrimiento de no ser correspondido (28);

- la cobardía del pecado (29) y la virtud de la abstinencia (30);

-la castidad (31).

En el Collar se aborda también el tema de la importancia del lenguaje, de su precisión y de la síntesis necesaria para expresar los sentimientos. El estilo de Ibn Hazm está entre los más claros y originales de la literatura árabe, comparable con el estilo de al-Ğāhị por ejemplo. El lenguaje utilizado en la obra a veces resulta ambiguo, al indefinir si se refiere a un hombre o a una mujer. Por ejemplo, el uso de referirse a mujeres con pronombres masculinos estuvo bastante generalizado.

Lo importante en la narración del amor no correspondido es la historia de este amor y el comportamiento que tienen el amante y la amada. En cualquier caso, el amor entre los seres humanos sigue siendo un signo de Dios. El amor también conduce al pecado y para evitarlo el hombre recurre a la ayuda de Dios. Se deduce que la virtud para el hombre consiste en evitar el libertinaje y en la resistencia para la mujer (al-șalăh).

En particular, en relación con el tema del amor y la figura del hombre y de la mujer amada, Ibn Ḥazm utiliza unos términos que cabe mencionar aquí. Por ejemplo: $i \underset{\bar{\alpha}}{d} h \bar{a} r$, cuando el hombre 
se manifiesta, pero con una máscara; qunū $\bar{u}^{\varsigma}$, el consuelo del hombre enamorado; garad, la pasión por celos del amante. El análisis de los temas literarios que se encuentran en el Collar así como en la poesía cortés no permiten establecer si el primero ha sido fuente directa de la segunda, o bien si se trata de ideas literarias en circulación dentro de un preciso marco de tiempo.

\section{La teoría del lenguaje de Ibn Hazm}

El interés de Ibn Hazm por el lenguaje se manifiesta ante todo en el estudio de la lógica, una disciplina que él cree útil para los fines de los estudios religiosos. Sin embargo, el autor considera necesario simplificar el lenguaje para que sea más comprensible. La lógica sirve para comprender plenamente el significado de las palabras y sus relaciones mutuas. Una vez conseguido esto, será posible comprender el verdadero sentido de los dichos del Profeta y de la palabra de Dios, distinguir lo verdadero de lo falso y, por fin, identificar al-burhān, la prueba de la existencia de un solo Dios.

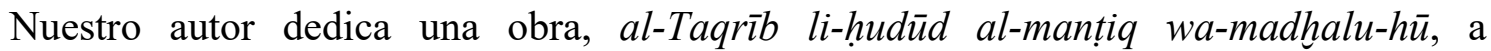
reflexionar sobre el pensamiento de los principales filósofos que vivieron en épocas anteriores. En particular, se ocupa del lenguaje en las secciones dedicadas a Porfirio y Aristóteles. Empieza analizando el sonido (șawt), que nos permite hablar. Ello es inicialmente una manifestación efímera sin sentido, que se convierte en portadora de significado (alfâd $)$ ) solo si designa cosas existentes o las califica. De hecho, todo excepto Dios está determinado por una definición o descripción.

Luego Ibn Hazm pasa a tratar las categorías aristotélicas y en lo que respecta al discurso, lo divide en expresiones simples y el acto concreto. Las primeras incluyen expresiones equívocas (al-asma $\bar{a}^{?}$ al-muhtalifa), inequívocas (al-asma $\bar{a}^{?}$ al-mutawāți $\left.{ }^{2} a\right)$, homónimos (al-

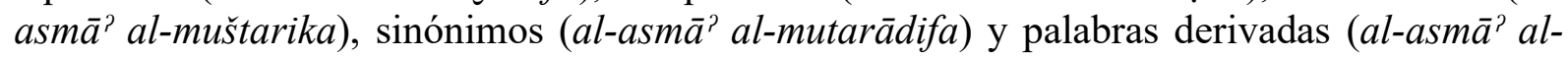
muštaqqa). El acto concreto consiste en palabras simples o palabras combinadas. Las últimas pueden dar lugar a una proposición predicativa (habar), interrogativa (istihbar), exclamativa ( $n i d \bar{a}^{\imath}$ ), un deseo ( $\left.r a \dot{g} b a\right)$ o una orden $(a m r)$. Solo la primera se puede evaluar en términos de verdadero o falso, las demás están exentas de esta evaluación.

Observando la escritura de Ibn Hazm la primera característica que se nota es el equilibrio perfecto entre uso de imágenes y claridad de exposición (ma $a^{\varsigma} \bar{a} n \bar{l}$ y alfād. $)$. Ibn Hazm mismo afirmó que se puede utilizar el lenguaje arbitrariamente (tahakkum bi-l-lisānn) mientras que se producen discursos inconsistentes (tašadduq fi l-kalām), pero eso solo revela retórica y ostentación (istițāla bi-l-bayān, riy $\bar{a}^{\prime}$ ). Las palabras verdaderas son las de Dios, ya que los hombres distorsionan el lenguaje. De ahí surge su esencia místico-religiosa y su ideología d̄āhirī, según la cual el valor del idioma reside en la verdad y la sinceridad del poeta y del registro lingüístico adoptado.

El lenguaje se usa en realidad para propósitos precisos, pero el origen del lenguaje (aṣl al-lugia) es divino. Si se inclina por las pasiones humanas, el lenguaje se vacía de su esencia, con el resultado de invalidar el idioma (ibtâl al-lugia). El uso del lenguaje nunca debe ser convencional (con tawqîf o iștilāh) porque el propósito del lenguaje es la comprensión (tafāhum). El lenguaje debe ser tomado como una manifestación externa (dָāhir) y su lectura intrínseca (bạtin) es solo artificial y pretenciosa.

Las palabras tienen un significado connotativo (dalīl) o bien un significado denotativo

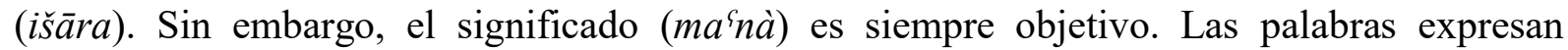
significados generales ( ${ }^{S} u m \bar{u} m \bar{a} t$ ) que, relacionados con experiencias concretas, adquieren una connotación precisa $(d a l i ̄ l)$. Tal teoría de Ibn Hazm se alinea con el principio clásico de Aristóteles de forma y sustancia. 


\section{Legado del 'amor cortés árabe': $a d a b$ y amor 'ud $\mathbf{c} \bar{\imath}$}

El término $a d a b$, cuya raíz recuerda el significado de 'nutrir' como por ejemplo nutrir el alma, hacía referencia originariamente al uso, costumbre o norma de conducta correcta y recomendada. Posteriormente pasó a designar la cortesía, la buena educación, reflejo del cambio de la sociedad musulmana de su origen inicialmente tribal a una vida refinada y culta, y comenzó a englobar tanto la poesía, los proverbios, las genealogías, la historia y las tradiciones de los árabes, como leyendas y narraciones de tipo moral, cuentos y fábulas, así como conceptos de carácter ético.

La narración del antiguo amor ${ }^{\complement} u \underline{d} r \bar{i}$, al cual Ibn Hazm hace referencia en el capítulo sobre la muerte del Collar, sigue un patrón común en los diversos autores: el poeta y su amada crecen juntos, se enamoran y sueñan con el matrimonio. Esto se les niega, o la promesa se rompe; así que la mujer se casa con un hombre más rico. El hombre-poeta permanece fiel a su amor, y literalmente 'muere' de pena consumiéndose por un sentimiento insatisfecho. Esencialmente, este amor consiste -como el descrito por Ibn Hazm- en un estado de ánimo y un código de comportamiento.

Conviene también recordar que el arte de Ibn Hazm se ha transmitido mucho más allá de la época cortés. Por ejemplo, hasta el siglo XIV con el Libro de buen amor de Juan Ruiz, testigo de cuánto duró en la Península el efecto de Ibn Hazm en las convenciones literarias relacionadas con el amor cortés. ${ }^{(3)}$

\section{Hipótesis de intertextualidad, interdiscursividad y factores comunes entre Ibn Hazm y la poesía trovadoresca}

El análisis de los temas literarios que se encuentran en el Collar, así como en la poesía cortés no permiten establecer si el primero ha sido fuente directa de la segunda, o bien si se trata de ideas literarias en circulación dentro de un marco de tiempo preciso.

Generalmente, el nivel de contaminación entre obras ha sido alto en la historia de la literatura, donde la intertextualidad se destaca como un procedimiento adoptado frecuentemente y con lo cual se construye una trama narrativa compleja. ${ }^{(4)}$ El estudio de la intertextualidad se basa en el deconstruccionismo elaborado por el filósofo Derrida: la observación de que significante y significado ya no representan una pareja fija con correspondencia única, por el contrario están bien separados y difícilmente pueden reunirse. En la práctica, existe una différance entre la obra, material muerto, y el texto, que se puede interpretar con una referencia continua de significados, su superposición, su juego de referencias y variaciones. ${ }^{(5)}$ Admitiendo esta diferencia-aplazamiento, numerosos críticos han analizado las estratificaciones textuales y han ofrecido diferentes definiciones de intertextualidad:

-como relaciones entre autor/texto/contexto (Kristeva y Barthes), por lo que un texto es de hecho una celosía y no puede separarse de su contexto. Además, cada texto-mejor dicho, cada intertexto- tiene siempre su doble, es decir, una doble esencia a nivel de significados, lo que debilita el papel del autor y su intencionalidad original;

-como una relación entre texto y lector (Riffaterre), donde el lector reconocería indicaciones del contexto en el texto y, si ha experimentado tales pistas, comienza a construir su imaginación y trata de resolver las ambigüedades de significado con su propia competencia;

(3) Castro (1954): The Structure of Spanish History, pp.429-445

(4) Brugnolo et alii, op.cit., pp. 284-291

(5) Ibidem, pp.324-326 
-como relación entre obras individuales y géneros (Genette), postulando la existencia de un primer arquitecto de referencia, al que se refieren los siguientes de forma explícita o implícita. Mediante un procedimiento transtextual, cada texto es la manifestación (hipertexto) de un hipotexto subyacente. Los signos de lo antiguo sobre lo reciente se pueden rastrear a través de la cita, a veces de la alusión o incluso del plagio. Nada se cancela de la raíz a la superficie, porque cuando se sobrescribe las huellas, sin embargo, no se pierden.

Este mismo razonamiento fue aplicado a la crítica literaria árabe por el marroquí Kilito en su El autor y sus dobles de 1988. Kilito afirma que el autor (el poeta) "se basa en un dibujo". (6) Las huellas de los que nos precedieron, incluso en el sentido literario, no desaparecen, sino que se absorben temporalmente y siempre están listas para manifestarse nuevamente: Exactamente como en la vida de los nómadas del desierto, donde el goteo del agua siempre resurge en la arena de los campamentos y el índigo siempre rezuma de los tatuajes. El papel del arte y la literatura, dice Kilito, es simplemente poner en orden estos elementos, antiguos y nuevos.

En cuanto a la obra de Ibn Hazm, nos ha llegado un único manuscrito con muchos pasajes corrompidos, el de Leiden, que fue editado en 1914 por Pétrof, traducido en 1931 al inglés por Nyk1, y traducido en 1933 al ruso por Sallier. Como alternativa a la costumbre de muchos estudiosos, que intervinieron en el texto para mejorar su inteligibilidad, García Gómez en su artículo del año 1941 ha sugerido analizar El Collar a través de las citas y reproducciones que se pueden encontrar en otros autores, sobre todo en el Diwān al-ṣabāba de Ibn Abī Hağāala ${ }^{(7)}$. En particular, resaltan unos pasajes que aparecen tanto en el faṣl $2^{\circ}$ del Prólogo del Diwān, titulado fì asbābi-hī wa 'alāmāti-hī, como en el capítulo sobre bābu 'alāmāti l-hubbi del Tawq. Además, los versos del Diwān, contenidos en la sección fì dikri l-muhibbinna l-d̄urafāi mina lmulūki wa-l-hulafầi, se encuentran en el Collar cuando trata del mismo asunto. También el capítulo $3^{\circ}$ fi dikri man 'ašiqa 'alà l-asmā’i del Diwān proporciona préstamos textuales tomados de la sección al-kalāmu fì mā’iyyati l-ḥubbi del Collar. García Gómez observa también que Ibn Abī Hağāla no solo marca algunos versos tomados de Ibn Hazm como anónimos -escribiendo kamā qìla-, sino que en otras ocasiones se los atribuye a sí mismo -presentándolos con qultu.

Hay otro autor cuya obra contiene rastros del Tawq. Se trata del Tazyīn al-aswāq de Dāwūd al-Anțākī. Sin embargo, aquí el eco del original se encuentra en dos pasajes solamente y a nivel de las palabras utilizadas: 1) el episodio del andalusí que vendió una esclava en tierra bereber; 2) el amor de Ibn Quzmān por Aslam b. ${ }^{\varsigma} \mathrm{Abd}$ al- ${ }^{\varsigma} \mathrm{Az} \overline{\mathbf{z}}$, pagado con la vida.

De todas maneras, es un hecho muy afortunado que haya sido plagio, porque nos ha permitido probar y verificar el contenido del único manuscrito del Collar que nos ha llegado.

Contaminación se ha observado también entre el legado árabe-islámico y las obras de Dante. Por esta razón, será útil recuperar los conceptos de intertextualidad e interdiscursividad, ya adoptados por la especialista en estudios sobre Dante, Maria Corti ${ }^{(8)}$, y proponerlos nuevamente entre Ibn Hazm y la poesía cortés.

La profesora planteó que el proceso de interdiscursividad hace posible recuperar la fuente directa de una noticia o información porque ya es parte de la cultura, mientras que los fenómenos intertextuales nos llevan a afirmar que un texto dado ofrece un modelo de estructura analógica a otro texto, pero esto no significa automáticamente que el texto-modelo pueda ser considerado fuente cien por cien del segundo.

\footnotetext{
(6) Kilito, op.cit., p.19

(7) García Gómez (1941): «El Ṭawq y el Diwān al-Șabāba», pp. 67-70

(8) Corti (1992): Dante a un nuovo crocevia.
} 
Tenemos evidencias de los fenómenos mencionados en unos factores generales y elementos comunes entre los temas y las ideas de la poesía romance y andalusí. Ambos han sido analizados por el profesor Corriente ${ }^{(9)}$ y concretamente se refieren a cuestiones de estructura estrófica, métrica, lingüística y a la temática. En relación con los temas tratados, observamos que la poesía andalusí ya había recuperado el repertorio árabe clásico. Por ejemplo, la estructura de la casida árabe, con sus descripciones (awșâf) que ofrecen la mejor oportunidad al literato para mostrar su arte, se integra en la estructura de la poesía omeya. Los sujetos principales en Ibn Hazm y en la poesía cortés siguen siendo el amado (habỉb) y el amante ( $(\bar{a} \bar{s} i q)$, a veces evocados por partes del cuerpo o vestidos. El segundo tema al que recurre es el amor, al que otorga diversos nombres: hubb, hawa, wudd. Este tiene un valor ambivalente porque da la vida y también causa varias enfermedades, con síntomas precisos, tanto a nivel físico como psicológico. El enamoramiento-pena genera comportamientos específicos del enamorado, sobre todo caracterizados por la sumisión, la cual está encauzada a la concesiónilusión de favores, o bien a obtener un mínimo de consideración por parte de la amada. El amor está reglado por dos códigos: ético, cuya ley es la obediencia a la amada, y estético porque el sentimiento ennoblece al hombre. La sede física del amor es el corazón que sobre todo sufre, y raramente se alegra. El escenario concreto que rodea las vicisitudes amorosas es urbano, una ciudad con su flora y fauna bien descrita; el escenario abstracto es metafísico y religioso, asociado con la mención de Dios, varias veces.

Tras el análisis del prof. Corriente, a favor de la hipótesis de intertextualidad e interdiscursividad, encontramos indicaciones específicas también reportadas por $\operatorname{Giffen}^{(10)}$ y aquí resumidas:

- el amor como fuerza capaz de hacer al hombre más generoso, valiente, y noble, y de modificar sus defectos de carácter;

- el sentimiento del amor procede junto con un deseo inalcanzable;

- el concepto del amor como enfermedad y sus síntomas: palidez, insomnio, falta de apetito, melancolía y probable locura;

- la importancia del secreto y los celos;

- el papel de ciertos personajes, como el espía, el mensajero, la persona de fiar;

- la actitud del enamorado semejante a un culto religioso;

- ocasionalmente, las denominaciones masculinas para referirse a la mujer;

- la posibilidad del sentimiento-enfermedad entre miembros de diferente clase social, como entre la amada (superior) y el enamorado (inferior). En el caso de Ibn Hazm, eso está justificado por la igualdad de todos los seres humanos ante Dios

\section{Paralelismos temáticos}

En cuanto a los paralelismos temáticos que nos permiten plantear la hipótesis de un legado árabe en la poesía cortés, Roger Boase ${ }^{(11)}$ ha analizado pasajes específicos de varias obras, a través de los cuales se desarrolla la teoría que afirma la existencia de una transmisión cultural entre las dos literaturas. En particular, este autor considera pasajes y obras de:

Bernart de Ventadorn (n. 1120-1130), hijo de un sirviente del Castel de Ventadorn en la región francesa del Lemosín, se dice que estaba enamorado de la mujer del vizconde de

(9) Corriente (1997): Poesía dialectal árabe y romance en Alandalús, pp. 41-69.

(10) Giffen (1992): «Ibn Hazm and the Tawq al-hamama», pp. 420-442.

(11) Boase (1992): «Arab influences on European Love-Poetry», pp.457-482. 
Ventadorn. Luego se trasladó a la corte de Enrique II de Inglaterra — a cuya mujer dedicó unos poemas líricos - y de Raymod V de Toulouse. Después de 1173 no se conocen más noticias sobre su vida. Bernart concibe la poesía como puro amor, sentimiento místico y puro sin referencias autobiográficas. La condición fundamental que él describe se resume en el "senhal", como sentimiento y vivencia interior simbólicamente representado a través de eventos naturales como la floración, el canto de alondras, los vientos. Estos no se refieren a presencias físicas, sino a una dimensión fantástica de la memoria que se mezcla con la soledad del corazón enamorado ${ }^{(12)}$.

Andreas Capellanus (Andreas de Luyères, n. 1150) probablemente debe su nombre a una transcripción errada de la palabra "cambellanus", por lo que entendemos que fue un dignatario de corte. Se cree que vivió a la corte de María de Champagne y después de Felipe Augustus, rey de Francia. Escribió el tratado De Amore o De arte honeste amandi, en tres libros, donde aborda cuestiones generales (la naturaleza del amor, sus efectos, como se adquiere el amor), y específicas según el contexto social de los amantes (como habla el hombre gentil a la mujer gentil o plebeya). Solamente puede amar quien sea cortes, así como el "fin'amor" o amor cortes nos hace corteses. El sentimiento siempre permanece insatisfecho,porque si fuera realizable, desaparecería. Recibió la condena de la Iglesia por haber teorizado que la experiencia de amor se encuentre fuera del amor conyugal. Murió en la primera década de 1200 .

Guillermo de Aquitania nació en 1071 y murió en 1126. Sucedió a su padre en 1085. Fue definido "vehemens amator feminarum", hombre audaz y guerrero ${ }^{(13)}$. Participó en una cruzada en Tierra Santa en 1101 y fue el primero en escribir poesías en lengua vulgar.

Se proporcionan, por cada autor, los relativos ejemplos distinguidos por temas a continuación.

\section{La actitud del amante}

Se puede comparar Bernart de Ventadorn con Ibn Hazm en los pasajes que siguen:

Bona domna, re no us deman

Mas que'm prendatz per servidor,

Qu'ie us servirai como bo senhor,

Cossi que del gazardo m'an ${ }^{(14)}$

[Buena Dama, yo nada pido/sino ser vuestro servidor,/os serviré como a mi señor,/decir el premio merecido. Trad. de Guillermo Díaz Plaja $\left.{ }^{(15)}\right]$

No es reprobable rebajarse ante quien amamos, pues en amor el más orgulloso se humilla.

No os maravilléis de que me someta en mi situación, pues antes que yo se sometió al-Mustansir ${ }^{(16)}$

Análogamente, sobre el tema de fidelidad:

Chantars no pot gaire valer

(12) Roncaglia (1961): La poesia dell'età cortese, pp. 278-279.

(13) Ibidem, pp. VII-IX.

(14) De Ventadorn (1966): Chansons d'amour, $\mathrm{n}^{\circ}$ 1, 11, pp. 49-52.

(15) López Martínez (2015): «Los poetas y sus temas», p. 104.

(16) Ibn Ḥazm (2010): El collar de la paloma, trad. García Gómez, p. 163. 
En agradar et en voler

Es l'amors de dos fis amans.

Nula res no i pot pro tener

$\mathrm{Si} \cdot 1 \mathrm{~h}$ voluntatz non es egaus ${ }^{(17)}$

[Poco puede valer el cantar/el amor de dos leales amadores está en agradar y en querer/nada puede ser provechoso/si la voluntad no es igual $\left.{ }^{(18)}\right]$

Me dicen: «iPor Dios! Dinos el nombre de aquel cuyo amor alejó de ti el sueño tranquilo.» Pero nunca. Antes de que logren lo que desean habría de perder la razón y afrontaría cualquier desventura ${ }^{(19)}$.

Además, en relación con la descripción del tipo de amor, notamos la caracterización del amor como fuerza natural superior a las convenciones sociales, (en este sentido incluido el amor extraconyugal) que da lugar a elevación moral. Por lo tanto, la cortesía no tiene nada que ver con la riqueza, pero con la nobleza de mente. Nace así una moral laica, con sus mandamientos, como en De arte honeste amandi por Andreas Capellanus ${ }^{(20)}$

Effectus autem amoris hic est, quia verus amator nulla posser avaritia offuscari; amor horridum et incultum omni facit formositate pollere, infimos natu etiam morum novit nobilitate ditare, superbos quoque solet humilitate beare ${ }^{(21)}$

[Este es el efecto del amor, ya que el verdadero amante no puede ser ofuscado por la avaricia; el amor hace que el rudo e inculto brille con toda hermosura, sabe también enriquecer a los de ínfimo nacimiento con nobles costumbres, y también suele proporcionar humildad a los soberbios].

Guillermo de Aquitania $^{(22)}$ describe los efectos del amor, como la fuerza de alterar las condiciones personales:

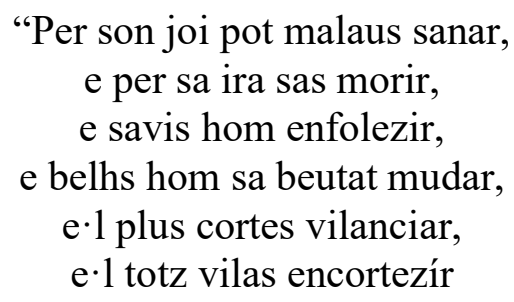

[El gozo del amor al enfermo puede sanar, pero por su ira el sano puede morir, el hombre sabio enloquecer, el bello perder su belleza, el más cortés volverse villano, pero el perfecto villano hacerse cortés.]

\section{Conclusiones}

Todos los ejemplos anteriores son testimonios de las interferencias entre el amor cortés árabe y europeo del siglo XII. Este último, sin embargo, fue animado por sentimientos liberales nuevos, remplazando los viejos ideales de caballeros medievales. Efectivamente, para aquellos

(17) De Ventadorn, op.cit., $\mathrm{n}^{\mathrm{o}}$ 7, pp. 15-17.

(18) Cfr. traducción https://poeticas.es/?p=355

(19) Ibn Hazm, op.cit., p. 153

(20) De Fuentes (1992): «El amor hace sutil al hombre», pp. 53-54. Texto y traducción.

(21) Cappellanus (1980): «De Amore,» 1.4.1, sobre las señales del amor: "Quis sit effectus amoris?".

(22) Guillermo de Aquitania. Canción IX Texto y traducción, apud De Fuentes (1992), op.cit.,p. 59. 
que vivían con ingresos sin trabajar y sin vínculos con el mundo productivo, dar y consumir eran signos de magnanimidad y cortesía, como opuesto de la vilenie plebeya. En este contexto, la Dama representa el polo de la vida cortés, mientras que la categoría de poetas incluye no solo a los nobles, ya que la poesía con el tiempo se convertirá en herramienta de promoción social. Por ejemplo, Peire Vidal fue hijo de un peletero, Aimeric de Peguilhan hijo de un comerciante de telas, de hecho, extraños a la vida de corte. Permanecen los rasgos típicos de la poesía árabe cortés como el culto a la mujer inalcanzable (domnei, midons) en el marco de una religión del amor; el tema de inferioridad, sumisión y humildad del hombre-sirviente; el amor no correspondido (amor desamatz) y amor distante (amor de lohn); el amor como ennoblecimiento (fin'amor); el secreto y uso de seudónimos (senhal), y el papel de los calumniadores (lauzengiers). Tomando en consideración la posibilidad de una lectura simbólica de todos los rasgos mencionados, Eric Kohler ${ }^{(23)}$ señaló que la relación entre dama y enamorado se podría interpretar como la trasposición literaria de la relación entre señor y vasallo, parcialmente confirmada por la utilización de designaciones masculinas para referirse a la amada. Por cierto, dicha relación también fue bien caracterizada por devoción e inferioridad, debido a la asimetría crónica del equilibrio de poder en la sociedad medieval, en la época de los trovadores.

Seguramente, el contacto de los árabes con los europeos afectó a la literatura española, matizándola con características singulares. Es necesario tener en cuenta la proximidad de las dos culturas, árabe y romance, en Córdoba y en toda la Península Ibérica. Fueron muchas la luchas por la conquista del poder, las rivalidades entre musulmanes y cristianos, a veces resueltas con políticas diplomático-matrimoniales como fue el caso en Navarra y León. Desde la Península Ibérica muchas contaminaciones e interferencias se trasladaron hacía el sur de Francia, sobre todo después de la batalla de Barbastro, cuando las cantantes incluidas en el botín de guerra fueron transportadas a las cortes francesas meridionales. De hecho, huellas árabes se encuentran también en otras literaturas, por ejemplo, en la francesa y trovadoresca. Los árabes influyeron en la forma y en el contenido de la creación literaria: estructura estrófica, métrica, lingüística, así como temática. Este artículo ha proporcionado ejemplos de paralelismos temáticos, justificados gracias a hipótesis de interdiscursividad e intertextualidad, entendidos como procesos que hacen posible recuperar temas y modelos, aunque la literatura anterior no pueda ser considerada una fuente directa al cien por ciento.

\section{Bibliografía}

BEARMAN, P. J., et alii (2004): The Encyclopaedia of Islam, vol. III, s.v. "Ibn Hazm”, Leiden: Brill

BOASE, R. (1992): «Arab influences on European love-poetry», en S. K. Jayyusi (ed.). The legacy of Muslim Spain, Leiden: Brill, pp.457-482.

BRUGNOLO S., COLUSSI D., ZATTI S., ZINATO E. (2016): La scrittura e il mondo, Carocci: Roma

CAPPELlANUS, A. (1980): De Amore, Graziano Ruffini (ed.), Milano: Guanda.

CASTRO, A. (1954): The Structure of Spanish History, Edmund L. King (trad.), Princeton: Princeton UP.

CHEJNE, A. G. (1984): «Ibn Hazm of Cordova on Logic», Journal of the American Oriental Society, 104-1, pp. 57-72

CORBERA, A., SENAC, P. (2018): Barbastro: Guerre sainte et jihad en Espagne, Paris: Gallimard.

CORRIENTE, F. (1997): Poesía dialectal árabe y romance en Alandalús, Madrid: Gredos

CORTI, M. (1992): Dante a un nuovo crocevia, Firenze: Le Lettere.

(23) Kohler (1976): Sociologia della 'fin d'amor'. 
FERREIRO, A. (1983): «The siege of Barbastro 1064-1065: a reassessment», Journal of Medieval History, 9/2, pp. 129-144.

GALMÉS DE FUENTES, Á. (1992): «El amor hace sutil al hombre. Ibn Hazm de Córdoba y la tradición románica», Anaquel de Estudios Árabes, III , pp. 53-54.

GARCÍA GÓMEZ, E. (1941): «El Ṭawq y el Diwān al-Ṣabāba», Al-Andalus VI-5, pp. 67-70

GARCÍA GÓMEZ, E. (1953): «La entrada de Ibn Hazm en el mundo oficial», Al-Andalus, XVIII-2, pp. 437-438

GIFFEN, L. A. (1992): «Ibn Hazm and the Tawq al-hamama», S. K. Jayyusi (ed.). The legacy of Muslim Spain, Leiden: Brill, pp. 420-442.

IBN HAZM DE CORDOBA (2010): El collar de la paloma, Emilio García Gómez (trad.), Madrid: Literatura Alianza Editorial

KILITO A. (1988):, L'autore e i suoi doppi, Torino:Einaudi

KOHLER, E. (1976): Sociologia della 'fin d'amor', Padova: Liviana

LIROLA DELGADO, J. PUERTA VILCHEZ, J.M. (2004-2017): Biblioteca de al-Andalus, s.v. «Ibn Hazm», vol.3, Almeria: Fundación Ibn Tufayl de Estudios Árabes, pp. 392-443.

LÓPEZ MARTINEZ, A. "Los poetas y sus temas". Literatura Medieval, 2 (2015), p. 104.

MAKKI, M. (1992): «The political history of al-Andalus», S. K. Jayyusi (ed.), The legacy of Muslim Spain, Leiden: Brill, pp. 36-55.

RONCAGLIA, A. (1961): La poesia dell'età cortese. Milano: Nuova Accademia Editrice.

VENTADORN, B. de (1966): Chansons d'amour, nº 1/ 11, Moshé Lazar (ed.), Paris: Carrefour, pp. 49-52.

Web:

https://poeticas.es/?p=355 (consultado 12/11/2020) 